\title{
Learning Management Systems in Higher Learning Institutions in Tanzania: Analysis of Students' Attitudes and Challenges towards the use of UDOM LMS in Teaching and Learning at the University of Dodoma
}

\author{
Lucian V. Ngeze \\ School of Virtual Education, \\ The University of Dodoma, Tanzania
}

\begin{abstract}
A number of higher learning institutions in Tanzania have implemented Learning Management systems (LMSs) to manage online teaching and learning. However, effective use by both learners and instructors has been hindered by many challenges. This paper analyzes the students' attitude towards the use of such systems with a focus on the University of Dodoma (UDOM). An online questionnaire was administered to sixty students from three different colleges who took different courses delivered in blended mode, with an online component through the University of Dodoma Learning Management System (UDOM LMS). The study found out that among the factors that hindered the use of the system, lack of skills to use the system and network issues were the key one. Students used their own laptops and mobile devices (mobile phones and tablets) to access the system. Students preferred being connected to the Internet using wireless modems than going through the college Local Area Network (LAN). To improve the use of the system, students suggested on improving the University network and training users on how the system works. There were also other suggestions such as uploading course materials and assessment activities on time, improving power outages and connectivity, and introducing Distance Learning programmes.
\end{abstract}

\section{General Terms}

Learning Management System, UDOM LMS

\section{Keywords}

Distance Learning Programmes, Internet Service Provider, Learning Management System, UDOM LMS, Moodle.

\section{INTRODUCTION}

The use of learning management systems (LMSs) in higher learning institutions has taken another direction as many institutions are installing the learning systems to help in the teaching and learning process. An LMS is a software tool designed to manage student interventions and hence provide access to online learning opportunities for both students and teachers. It relies on the Internet to deliver educational courses and has many tools: delivery of learning content, tracking activities in progress, assessment, communication and content creation [1]. LMSs are classified into three categories: proprietary systems that are commercial (e.g., Blackboard and Desire2Learn); free/open source systems that are freely available to users, customizable and supported by a network of programmers around the world (e.g., Moodle and Sakai) [1]; and in-house systems which are evolved by system developers within a particular organization or institution to serve the purpose of delivering courses over the Internet. Any learning management system offers different learning styles to match the needs of the different learners [2]. LMSs are now being used by many higher learning institutions worldwide as tools commonly used in the delivery of courses to both on campus and off campus students. The system brings together content creation and delivery, communication, assessment as well as administration into a single platform deployed over the Internet [3]. A study made by Educause on the use of LMS by instructors and students reported that both users value the use of the system as an enhancement to the teaching and learning experiences, with only a few of them making effective use of them [4] i.e. allowing institutions to manage a large number of fully online or blended courses.

In Tanzania, higher learning institutions have adopted such systems to ease course delivery to students in different settings. Others are making efforts to implement them to deliver courses and programmes online. The University of Dar es Salaam (UDSM), for instance, deploys Moodle for offering blended learning courses to its postgraduate students through its centres in Mwanza, Arusha, and Dar es Salaam. Despite the good progress, the system has not been deployed to harness its full potential in the teaching and learning process. Challenges such as slow internet connectivity, unavailability of instructors during online sessions and some technical issues hinder its effective use [5]. Students at Mzumbe University (MU), where Moodle is used, appreciate the use of the system for blended learning since it creates flexibility and interactivity between learners and instructors. There are several challenges which hinder the effective use of the system at MU. From the students' perspective, the challenges include: Internet connectivity; inability to deliver some of the subjects (Mathematics and other practical subjects) as efficiently as other subjects; teachers' pedagogical weaknesses and inadequate guidance; inadequate computer laboratories and unreliable power supply that makes the system unavailable in some instances [6].

The University of Dodoma adopted Moodle LMS from 2008, since when the system has been used by students in colleges with infrastructure for their learning activities and interactions with the instructors. This paper examines the attitude of students towards it use and the challenges they face when they use the system.

\section{METHODOLOGY}

An online questionnaire was used as an instrument to collect data. Sixty (60) students from three colleges of the University of Dodoma participated. The colleges where participants came from were Informatics and Virtual Education (CIVE) with 40 participants $(66.7 \%)$ taking Bachelor programmes in Computer Engineering and Information Systems; College of Humanities and Social Sciences (CHSS) with 12 (20\%) participants pursuing Master of Business Administration and College of Education (CoED) with 8 participants (13.3\%) 
taking Bachelor of Education with ICT (BED ICT). The participants were students who participated in some courses conducted in blended mode with an online component using UDOM LMS. The courses and their corresponding colleges are shown in Table 1.

Table 1: Courses and their respective hosting Colleges

\begin{tabular}{|l|c|l|}
\hline Course Name & Course Code & College \\
\hline Computer Maintenance & CN 310 & CIVE, CoED \\
\hline $\begin{array}{l}\text { Very Large Scale } \\
\text { Integrated Circuits }\end{array}$ & TN 423 & CIVE \\
\hline $\begin{array}{l}\text { IT and Business } \\
\text { Computing }\end{array}$ & MS 612 & CHSS \\
\hline
\end{tabular}

The survey showed that $78.3 \%$ of the participants were first time users of UDOM LMS, while $21.7 \%$ had done some online courses before.

Three sets of questions helped in the analysis and presentation of results. The first set consisted of questions about UDOM LMS, access and usage; the second set asked for information on network providers commonly used among the participants, and the last set had open-ended questions in which participants were required to write their suggestions, comments and feedback.

\section{RESULTS}

\subsection{Knowledge about UDOM Learning Management System}

There was a question that asked participants how they came to know about UDOM LMS whereby $80.9 \%$ said that they knew it through their instructors; $17 \%$ knew about it from the University website, and only $2.1 \%$ came to know about through the training that was given about UDOM LMS usage.

The study revealed that the majority of the participants used their own laptops, while a smaller number relied on their smartphones or tablets as demonstrated in Figure 1. None of the participants used computers from the computer laboratories for accessing the system.

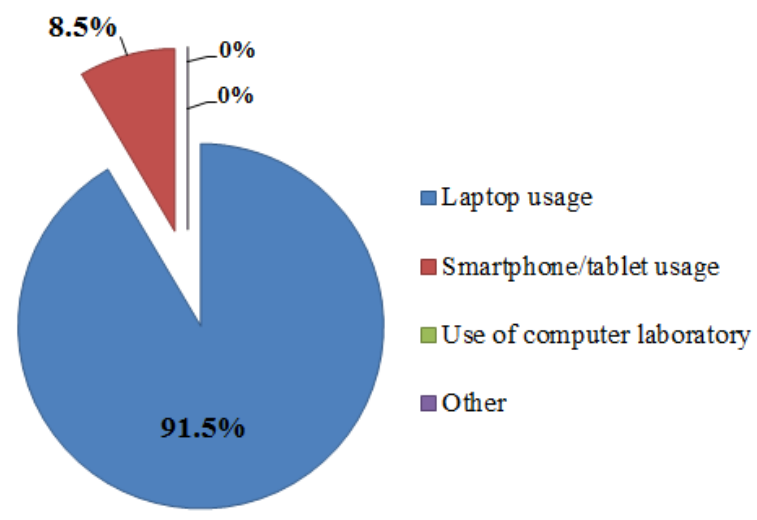

Figure 1: Use of different devices to access UDOM LMS

\subsection{User interface and Navigation}

The study aimed at finding the user friendliness of UDOM LMS. Out of the total participants, $61.2 \%$ found that the interface was user friendly, while it was somehow user friendly to $26.5 \%$ of the participants, with only $12.3 \%$ finding it hard to use the interface. Navigation between pages was assessed to determine its ease and difficulty. A big part of the participants $(46.7 \%)$ found it easy to navigate. Figure 2 displays the ease and difficulty of navigation between system pages.

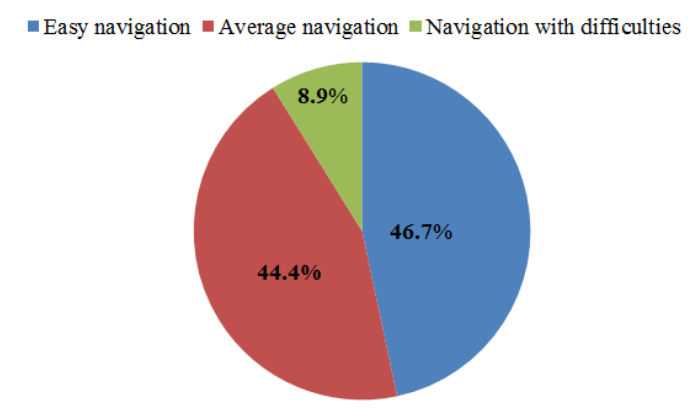

Figure 2: Ease of navigation between pages of UDOM LMS

\subsection{Network Usage}

Accessing contents and attempting any assessment tool in UDOM LMS involved connection to the Internet. Although there was a connection between the technical knowledge of the computer users (students) and their ability to use the system according to Bertea (2009) [7]. The researcher inquired the participants on how they connected to the Internet. Many participants connected to the Internet using modems. The college LAN proved not to be useful to students as no one used it to access learning resources.

Table 2: Internet connection method

\begin{tabular}{|c|c|}
\hline Connection method & $\begin{array}{c}\text { Percentage of } \\
\text { Participants }\end{array}$ \\
\hline $\begin{array}{c}\text { Connecting a modem to the } \\
\text { device }\end{array}$ & $70.2 \%$ \\
\hline $\begin{array}{c}\text { Tethering/Wi-Fi from mobile } \\
\text { devices }\end{array}$ & $29.8 \%$ \\
\hline Connecting to the College LAN & $0 \%$ \\
\hline Others & $0 \%$ \\
\hline
\end{tabular}

The commonly used Internet Service Providers are Vodacom, Airtel and Tigo (Figure 3). In this list, Vodacom is used by the majority of participants $(56 \%)$ because of its good services, and promotions.

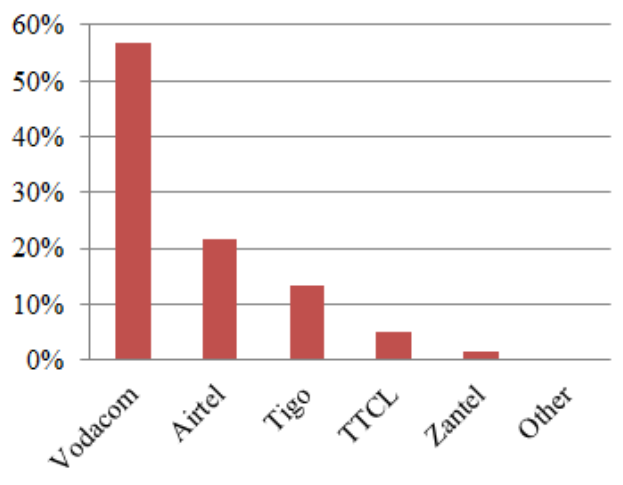

Figure 3: Internet Service Providers

In line with the Internet service providers, the speed of loading the system pages was also assessed, whereby, $12.8 \%$ of the participants said that the Internet connection had a very high speed, $59.6 \%$ said that it was high, while $23.4 \%$ said the connection was slow and $4.3 \%$ said that the connection was very slow. 


\subsection{Effective use of UDOM LMS in Teaching and Learning}

To be able to effectively evaluate the use of any system in teaching and learning, students have to be part of the process. In this regard, participants were asked whether, after interacting with the system in doing their courses, they really had obtained skills to use UDOM LMS effectively for educational purposes. The majority of the participants, as illustrated in Figure 4, had obtained skills to use the system in the process, while only $2.8 \%$ did not have any skills to use the system.

\section{Enough skills average skills $\quad$ No skils}

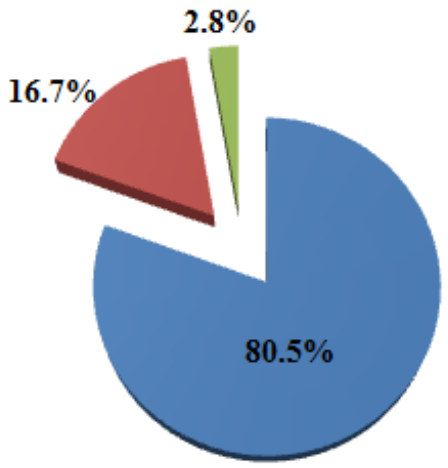

Figure 4: Skills to effectively use UDOM LMS for
education

It was clear, therefore, that after using the system in accessing courseware, students acquired knowledge and skills to do other activities related to management of courses and course assessment. Students with skills to use the system could download course materials, upload activities (assignments), and engage in online discussions through forums and in doing activities such as online quizzes. It is evident that the response of the students in using the system was positive. This is in line with the research done by Alhothli (2015) in [8].
The study aimed at examining the attitudes of students in using UDOM LMS at the University of Dodoma and the challenges they faced while using it. The findings advocated that many students knew about UDOM LMS and accessed it through their own devices (laptops, mobile phones and tablets). The study also revealed that students accessed the system for downloading lectures, attempting online quizzes, submitting assignments and engaging in online discussion forums. Most of the students agreed that if UDOM LMS had been well implemented, it would have helped in improving the teaching and learning activities in the University.

Findings also indicated that instructors did not update their lectures and assessment activities (quizzes, assignments) often. Uploading of the lectures takes time. This hinders students from using the system. Assessment activities made students engage in the use of the system which eventually made it active.

The study highlighted several challenges that hindered effective use of the system by students. These included network issues - connectivity and speed; and power outage problems. The study proved that students did not use college LAN while accessing UDOM LMS. This was because LAN in all colleges was not perfectly configured to route the traffic generated within the University. A high speed Internet connection and a stable power supply was the key solution to the use of the system in a scattered campus mode.

\section{SUGGESTIONS TO IMPROVE ACCESSIBILITY AND USE OF UDOM LMS}

The study required students to give their own suggestions for improving accessibility reachability of the system, and its efficient use. Figure 5 highlights the suggestions given. The suggestions given by students are set in six groups.

\section{DISCUSSION}

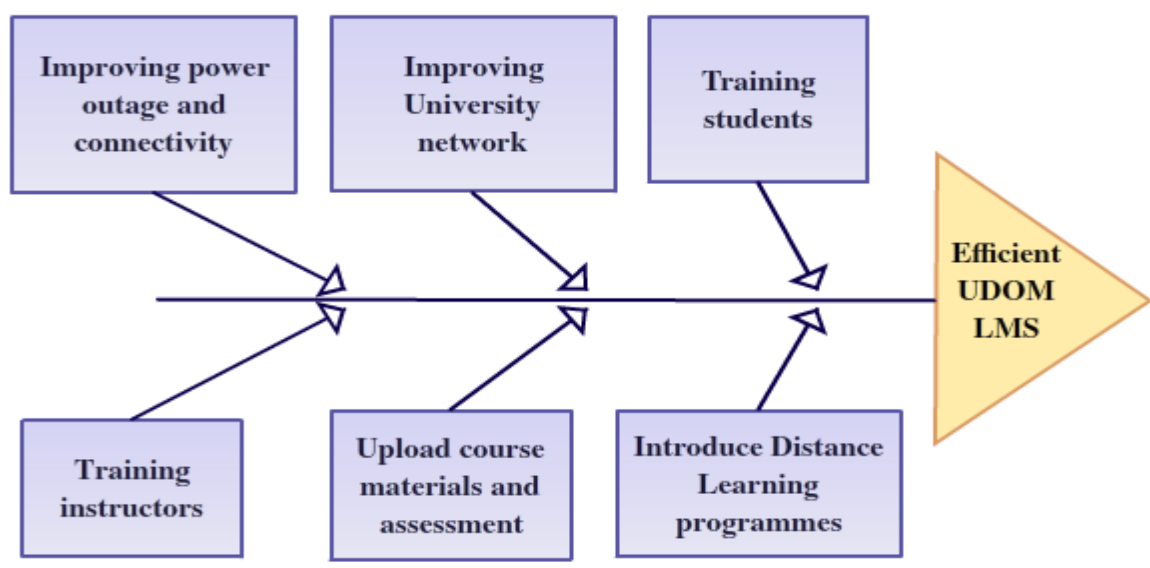

Figure 5: Suggestions to improve UDOM LMS

UDOM LMS is hosted in the main server that serves other systems. Because of frequent power outages and connectivity issues, the system goes down in such situations. If this is resolved, the system will be up and running all the time. It has been shown that students do not use University LAN. Improving University network will help in increasing the number of users that even computers in the college computer laboratories will be used. However, provision of such infrastructure may not guarantee maximum usage of the system [9]. Users need to be emphasized on the importance of improving their teaching and learning techniques. Other factors which determine the acceptance of learning management systems are suggested by Luoga (2014) in [10]. Quality of the system in terms of functionalities, 
interactivities and user-friendliness play a key role in user satisfaction. Moreover, if the attitude of the instructor towards the use of the system is good, and that the materials uploaded are of good quality to ensure effective learning, students will always tend to use the system.

\section{CONCLUSION}

The use of Learning Management Systems in teaching and learning is of great importance to both students and teachers. LMS can help teachers save time in many activities especially on the assessment of students. The time spent by teachers on preparing coursework especially in large classes can be reduced significantly by making use of the system where important assessment activities can be done automatically by the system when students interact with it. This was strongly accepted by a big percentage $(73.5 \%)$ of the participants who were involved in the courses which were partly taught using UDOM LMS. Improvement of the system and the enabling infrastructure needs to be done regularly to support different activities that increase interaction between students and teachers as well as amongst students. It is also useful to distant students who may be doing blended learning. These observations are important to institutions which are trying to start using learning management systems for course delivery. In the future, other services which are important to the students need to be integrated in the system. Such services include: providing distance learning activities, provision of video tutorials for different subjects and posting of previous university examination papers and other announcements.

\section{ACKNOWLEDGMENTS}

I would like to thank all respondents (my students from the courses I taught them) for their participations in our survey. Thank you for the inputs to the questionnaire I posed to you. Special thanks to Mr. Hassan Seif for the guidelines he provided during the analysis of the data. Thank you my friends Soviphea Chenda and Maura Loew for editing my manuscript and giving very useful comments to improve my work.

\section{REFERENCES}

[1] Babo, R. and Azevedo, A. 2012. Higher Education Institutions and Learning Management Systems :
Adoption and Standardization. Pennsylavia: Information Science Reference, 2012.

[2] Smaldino, M. et al., 2005. Instructional Technology and Media for Learning. New Jersey: Merrill Prentice Hall.

[3] Kats, Y. 2010. Learning Management System Technologies and Software Solutions for Online Teaching: Tools and Applications. New York: Information Science Reference.

[4] Dahlstrom, E., Brooks, D. C. and Bichsel, J. 2014. "The Current Ecosystem of Learning Management Systems in Higher Education: Student , Faculty , and IT Perspectives," Louisville, CO.

[5] Mtebe, J. S. and Raphael, C. 2013. "Students ' experiences and challenges of blended learning at the University of Dar es Salaam , Tanzania," Int. J. Educ. Dev. using Inf. Commun. Technol., vol. 9, no. 3, pp. 124-136.

[6] Nalaila, S. and Almasi, M. 2014. "Blended learning Application at Mzumbe University-Tanzania: Students' Perspective," in The 2014 eLearning Innovations Conference, pp. 1-119.

[7] Bertea, P. 2009. "Measuring Students' Attitude Towards e-Learning. A Case Study," in Conference on e-Learning and Software for Education.

[8] Alhothli, N. I. 2015. "Investigating the Impact of Using MOODLE as an E-Learning Tool for Students in an English Language Institute," University of Montana ScholarWorks.

[9] Sherbib, M. et al, 2012. "Factors Influencing the Use of Learning Management System in Saudi Arabian Higher Education: A Theoretical Framework," High. Educ. Stud., vol. 2, no. 2, pp. 125-137.

[10] Lwoga, T. E. 2014. "Critical success factors for adoption of web-based learning management systems in Tanzania," Int. J. Educ. Dev. using Inf. Commun. Technol., vol. 10, no. 1, pp. 4-21. 